\title{
Um Modelo de Malfeitos de Colarinho BranCo DENTRO de OrganizaçốES
}

\author{
VALdir MELO' \\ Instituto de Pesquisa Econômica Aplicada - IPEA - Brasil \\ $\approx$
}

RESUMO

Um modelo simples, como esse exposto neste texto, explica cometimento de delitos e malfeitos de colarinho branco dentro de uma organização. Ajuda a se identificarem dificuldades de prevenir e debelar tais malfeitos intraorganizacionais. Elas resultam de: condições que facilitam a ocorrência de malfeitos; aspectos que levam a descoberta tardia de malfeitos ocorridos ou levam a nunca serem descobertos; aspectos que prejudicam a investigação e a definição de pessoas suspeitas a indicar em ação judicial; condições que prejudicam a ação judicial e a condenação. Ademais, o modelo inspira algumas considerações sobre o caso da Petrobras e o cartel de empresas.

Palavras-Chave: Delitos de colarinho branco. Crime em organizações. Malfeitos. Dificuldades de prevenir e de debelar. Petrobras.

\section{INTRODUÇÃO}

Este texto expõe um modelo simples (nem algébrico, nem gráfico, mas narrativo) que explica cometimento de delitos e malfeitos de colarinho branco dentro de uma organização estabelecida legalmente. Emprega-se o termo genérico 'malfeito' (à maneira de wrongdoing na literatura técnica estrangeira) para designar violações normativas menos graves do que delitos (contravenções, res-

1 Este texto expõe parte dos resultados de estudos feitos como Pesquisador-Visitante no Laboratório de Análise da Violência (LAV) da Universidade Estadual do Rio de Janeiro. A acolhida e a oportunidade concedida devem-se aos diretores do LAV, Ignacio Cano e João Trajano Sento-Sé, a quem o autor agradece. O programa de capacitação oferecido pelo Ipea a seus técnicos em planejamento e pesquisa viabilizou a estadia de pesquisa. $\mathrm{O}$ autor também agradece aos pesquisadores Almir de Oliveira Junior e Daniel Pitangueira de Avelino, aos participantes de seminário no Ipea em 18 de novembro de 2016, e a Albino Rodrigues Alvarez, por comentários inspiradores e por proveitosas observações sobre versões anteriores; à psicóloga e economista Cristiana Pizarro da Silva, por chamar a atenção do autor para a importância do papel da sedução em malfeitos de colarinho branco; e a Felix Lopez por ter indicado e facilitado o acesso a obras técnicas pertinentes. No entanto, eles não respondem pelos enunciados ou juízos expressos no texto e talvez até divirjam de alguns. 
ponsabilidade civil, transgressões administrativas, violações substanciais da ética). Às vezes, também para designar violações normativas em geral, incluindo delitos, quando não tem importância distinguir. Adota-se no texto uma ótica das ciências sociais, não do direito e da legislação.

O modelo chama-se 'modelo de seção de operações veladas'. A organização do texto começa por tratar de uma motivação do modelo, na seção 1: o modelo serve para refletir-se sobre as dificuldades de prevenir e debelar delitos e malfeitos de colarinho branco dentro de organizações. A seção 2 expõe previamente certas características e elementos do modelo. Este é descrito na seção 3. Discorre-se sobre dificuldades de prevenir e debelar malfeitos intraorganizacionais de colarinho branco na seção 4. A seção 5 reflete sobre o caso da Petrobras e o cartel de empresas, onde tecem-se algumas considerações inspiradas pelo modelo. Seguem-se comentários finais.

\section{Motivação do Modelo}

As dimensões das dificuldades nas tarefas de prevenir, detectar, investigar e debelar delitos e malfeitos de colarinho branco precisam ser mais bem apreciadas.

A variedade de espécies de malfeitos de colarinho branco é barreira a uma exposição simples e curta dessas dificuldades. Uma compreensão abrangente do fenômeno requer estudar-se, entre outras coisas, como se formam organizações ilícitas, como se desenvolvem redes permanentes de transações entre praticantes de malfeitos pertencentes a organizações distintas (lícitas ou ilicitas, e suas combinações), como evoluem mercados e segmentos sociais dedicados a atividades transgressoras de normas. Quase toda sociedade moderna tem uma subsociedade ou submundo de malfeitos, no sentido de generalizar a expressão 'submundo do crime'. 'Crime' generaliza-se para 'malfeitos', porque muitas atividades dedicam-se a ilicitudes menos graves; e 'submundo' generaliza-se para 'subsociedade', porque nessa parte pouco conhecida da sociedade pode não haver somente atividades econômicas, mas haver também atividades sociais em geral (inclusive uma cultura própria, de ilicitude, com seus costumes, instituições, crenças e valores).

Tendo em vista superar parcialmente essa barreira, é frutífero limitar inicialmente uma investigação intelectual a um espectro mais estreito de 
possibilidades de malfeitos. É o que faz o modelo exposto mais adiante, que se limita a abordar o cometimento de malfeitos intraorganizacionais. Sendo modelo, simplifica e, por isto, não abarca todas as possibilidades, mesmo dentro de seu escopo. No entanto, é instrutivo e inspirador de reflexões.

Em particular, a respeito as dificuldades de prevenir e debelar malfeitos de colarinho branco, pode-se perceber que dificuldades importantes surgem no âmbito de práticas intraorganizacionais. As principais dificuldades resultam de: condições que facilitam a ocorrência de malfeitos; aspectos que levam a descoberta tardia de malfeitos ocorridos ou levam-nos a nunca serem descobertos; aspectos que prejudicam a investigação e a definição de pessoas suspeitas a indicar em ação judicial; condições que prejudicam a ação judicial e a condenação.

\section{Características e Elementos do Modelo}

É um modelo de aspectos estruturais de situação; ou seja, refere-se a condições intraorganizacionais que permitem ou encorajam certos tipos de comportamentos. Incorpora elementos de Ekman (1992), de Coleman (1994), de Mitnick e Simon (2005) e de Bunt (2010). Entre as noções a que recorre estão aquelas de pessoa cativante, credulidade, sedução e dissimulação.

A noção de pessoa aparentemente normal ou mesmo cativante, mas que tem pouca ou nenhuma consciência moral vem de Hare (1993). Greenspan (2009, p. 151-152) discorre sobre a extensão em que as pessoas são crédulas, considerando também o papel do afeto na credulidade. Há muito de interesse sobre o papel da sedução em Wrong (1988, p. 28-29), em Giannetti (1997, p. 178-181), em LeBor e Boyes (2000, p. 15-17) e em Mitnick e Simon (2005, c. 10); e sobre o papel da dissimulação em Ekman (1992) e em Giannetti (1997, p. 163-165). Algumas experiências instrutivas de iludir coletividades descrevem-se em Blumberg (1989), Bogdanich (1991), Sparrow (1996) e LeBor e Boyes (2000).

Duas experiências de sedução em vasta escala têm como responsáveis: Ken Lay, o carismático presidente da falida empresa de energia Enron; e Bernard Madoff, o respeitado e afável presidente de outra empresa falida, a Bernard L. Madoff Investment Securities. As duas organizações quebraram em consequência de práticas de malfeitos de colarinho branco. Relatam a En- 
ron os livros de Bryce (2002), Fusaro e Miller (2002), Fox (2003) e McClean e Elkind (2003). Sobre Madoff leiam-se os livros de Arvedlund (2009), Oppenheimer (2009) e Strober e Strober (2009).

Para simplificar a exposição do problema, o modelo abarca somente possibilidades de malfeitos praticados dentro de uma organização lícita. Visa mostrar como alguns membros da comunidade interna desta podem formar uma equipe dedicada a praticar malfeitos. Ou seja, como pode surgir uma 'seção de operações veladas', expressão eufêmica a indicar que os praticantes atuam de maneira encoberta, procurando evitar que o restante da comunidade se dê conta dos atos ilícitos.

\section{O Modelo de Seleção de Seção de Operações VELADAS}

\section{I. PRESSUPOSTOS}

Façam-se três suposições simplificadoras sobre a organização lícita que é vitimada:

i) Direta ou indiretamente, todos na organização trabalham com dados, obtendo-os, verificando-os e registrado-os; ou alterando-os para revisá-los, corrigi-los ou invalidá-los. Os dados têm grande valor econômico, ora por serem registros de quantias financeiras, ora por serem informações identificadoras de beneficiários a quem a organização serve.

ii) Há três estratos de hierarquia organizacional: funcionários, chefes intermediários e dirigentes. Nesta ordem, membros de cada estrato são subordinados a algum membro do estrato seguinte.

iii) O escopo das prerrogativas de cada cargo ou função limita a extensão em que cada indivíduo sozinho pode prejudicar a organização. Mesmo que o indivíduo seja um chefe ou dirigente. Limita a magnitude do prejuízo que a organização pode sofrer ela mesma ou pode causar a clientes e terceiros. Portanto, é um dispositivo institucional de segurança.

Façam-se quatro suposições simplificadoras sobre os malfeitos e seus praticantes:

iv) Os malfeitos consistem em desviar benefícios financeiros ou materiais da organização em favor dos praticantes. 
v) Não são malfeitos de tipo que se pratiquem uma única vez, de uma vez por todas; são praticados continuamente ao longo de considerável tempo, subtraindo-se muitas vezes quantias em grandezas pouco prováveis de chamar a atenção de cada vez.

vi) Podem tomar a iniciativa de praticar malfeitos indivíduos sozinhos que pertençam a qualquer um dos três estratos hierárquicos. Assim, uma 'seção de operações veladas' começa com um indivíduo fundador.

vii) Realizar acesso escondido e não detectado a prerrogativas do cargo de outra pessoa gera um risco muito alto, de modo que os potenciais praticantes de malfeitos excluem esta opção.

\subsection{DESENVOLVIMENTO}

Veja-se agora como pode surgir e desenvolver-se uma 'seção de operações veladas'.

Por hipótese, um indivíduo sozinho só pode praticar malfeitos dentro do escopo de seu cargo ou função, dentro de sua competência funcional. Tendo em vista isto, um praticante de malfeitos precisa neutralizar o dispositivo institucional de segurança, caso seja ambicioso e pretenda abocanhar um naco grande da riqueza a circular na organização. Um dirigente ou chefe intermediário mal intencionado precisa superar a barreira para agir representada por sua dependência de funcionários que dão pareceres jurídicos, fazem análises econômico-financeiras, realizam registros contábeis, conferem os documentos de pretendentes a benefícios etc. De modo semelhante, um funcionário mal intencionado precisa superar a barreira para agir representada por sua dependência de verificações e autorizações de seu superior.

Sendo assim, um dirigente que pretenda praticar malfeitos indo além do escopo de seu cargo precisa converter para seus propósitos um ou alguns chefes intermediários. Estes, por sua vez, se precisarem de ações que extrapolem os escopos de seus cargos, terão que converter para seus propósitos um ou alguns funcionários. Naturalmente, um dirigente, chefe ou funcionário pode aliciar outro do mesmo estrato hierárquico.

Um funcionário ou um chefe intermediário não tem o poder de dar ordens a seu superior. Para convertê-lo a seus propósitos, tem três maneiras: subornar, convencer a aderir ou iludir. Descarte-se como pouco provável, 
embora possível, a alternativa de ameaçar e chantagear o superior por anos a fio. Convence-se à adesão demonstrando as vantagens a obter e o baixo risco de ser detectado, além de propor repartição delas.

Iludir importa em exibir ou entregar ao superior informaçôes incompletas (com omissões), errôneas, enviesadas ou enganadoras. Estas induzem quem recebe a decidir de certa maneira, aquela desejada pelo praticante de malfeitos. Iludir resulta em manter honesto o superior, mas tornando-o instrumento involuntário e sem suspeição das operações de suporte aos malfeitos. O superior aprova o que julga ser trabalho competente, honesto e benéfico à organização.

Para ter sucesso em iludir, o subordinado precisa abusar da confiança do superior, aproveitar-se de que este não tem condições de examinar e verificar todas as informações dos documentos que assina. Se o superior tiver condições de verificar, o subordinado precisa ganhar imerecidamente grande confiança do superior, de modo que este se convença de ser desnecessária a verificação. Para conseguir, talvez o subordinado tenha que seduzir o superior, processo que será explicado mais adiante.

Um superior mal intencionado tem também as alternativas de subornar o chefe ou funcionário dependente, convencê-lo a aderir ou iludi-lo. Além disso, pode dar ordens. Se o subordinado se der conta de que as ações comandadas dão suporte a malfeitos e resistir a cumpri-las, o superior pode pressioná-lo (Stone, 1975, p. 167; Coleman, 1994, p. 209). Inicialmente, incomodando-o em processo de rebaixamento de imagem. Por exemplo, de vez em quando deixando 'escapar sem querer' dentro da organização a informação de que o funcionário é relapso ou incompetente.

Caso precise aumentar a pressão, o superior pode molestá-lo por meio de notas baixas em avaliações de desempenho; pode negarlhe premiações e benesses funcionais; pode removê-lo para atividades ou departamentos incômodos etc. O subordinado que não concorda é acusado de não cooperar com a equipe; não recebe indicações para boas missões e tarefas nem é promovido (Coleman, 1994, p. 208-209). E paira sobre ele a ameaça de retaliações ou de demissão (Stone, 1975, p. 167; Coleman, 1994, p. 208). 
Em suma, uma 'seção de operações veladas' pode surgir e desenvolver-se na organização em várias direções na linha hierárquica: de baixo para cima ou do meio para cima; de cima para baixo ou do meio para baixo; e também do meio para cima e para baixo. Em qualquer caso, por meio de alguma seleção ou combinação de estratégias de convencer a aderir, subornar, iludir, pressionar e seduzir. Em perspectiva levemente diferente (Schneier, 2006, p. 140): oportunidade, emoção ou coerção; isto é, oferecer ou apontar oportunidades, recorrer a emoções e afetos ou empregar coerção.

\subsection{PROCESSO DE SEDUÇÃO}

Sedução é ganhar o coração da pessoa-alvo. Quando visa praticar malfeitos, o sedutor finge comungar valores, interesses ou objetivos com o seduzido ou finge preocupar-se com o bem profissional ou pessoal deste. Tal processo tem a vantagem de influenciar sem enfrentar resistências, pois o influenciado desconhece as intenções do sedutor e faz escolhas julgando fazê-las livremente diante de opções atrativas (Wrong, 1988, p. 28-29; Mitnick e Simon, 2005, p. 221).

Seja um processo de sedução de superior para subordinado. É construído demoradamente ao longo do tempo, após o superior ter escolhido o alvo. Tem pelo menos duas fases. Na primeira, o sedutor, de modo cuidadoso, em tom quase de confissão íntima, declara ter notado e admirar a inteligência, ou a competência profissional ou a excepcional habilidade do subordinado-alvo. Gradativamente, expressa esses elogios mais vezes, com mais firmeza. Mostra regular interesse pelas habilidades e pelo suposto desempenho excelente do subordinado. Depois que este não se encabula mais, o chefe talvez faça os mesmos elogios da pessoa-alvo perante colegas desta e até perante um ou outro chefe.

Na segunda fase, o chefe convida o subordinado-alvo para jantares a dois, onde representa um papel de trocar ideias com o subordinado em situação relaxada e longe da curiosidade dos demais membros da organização. Na verdade, visa a construção mútua de aproximação e conhecimento pessoal. Discutem aspectos da organização e o superior pede conselhos ao subordinado. A certa altura, aparentando abrir sua intimidade pessoal, o chefe toca em problemas familiares e, por exemplo, menciona as próprias dificuldades com a esposa ou com um filho rebelde. Dificuldades que talvez não existam, mas o alvo da sedução, não podendo saber, acredita (Mitnick e Simon, 2005, p. 234). 
Tempos depois, o subordinado é levado a festas de aniversário de casamento do superior, da filha deste etc. Enfim, cria-se uma relação em que o subordinado sente-se profundamente valorizado como profissional e admirado pelo superior; mais do que isto, sente-se uma pessoa querida por este e possivelmente pela família deste.

Depois de seduzido, o subordinado confia cegamente no superior, pessoa que talvez ame como se fosse um pai sábio. A partir daí, o superior tem ascendência afetiva para sugerir ligeiras modificações nos termos dos relatórios, planilhas ou pareceres técnicos que o subordinado redige, pedir que retarde a entrega etc. Em determinadas ocasiões, o superior alega querer contornar possíveis conflitos ou crises graves na organização e solicita parecer bem diferente do que o subordinado redigiria. Mas a confiança deste no superior é imensa e este atende aos pedidos sem a mínima relutância ou o menor traço de dúvida sobre a correção deles (Mitnick e Simon, 2005, p. 234, 236).

Pode ocorrer que um subordinado seduza o superior. Porém, é pouco provável que ocorra da maneira descrita acima, a qual tira partido da ascendência de quem convida sobre o convidado. A menos que o superior seja pessoa simples e acessível, há uma barreira psíquica a que o subordinado o convide para jantar depois do expediente. A diferença de renda e de status é impedimento a que o superior frequente sozinho (ou com seu cônjuge) festas em residência do subordinado. Imagine-se que o funcionário é advogado altamente competente na organização, com salário de $\mathrm{R} \$$ 25 mil por mês; e que o superior, sendo diretor perceba $\mathrm{R} \$ 200$ mil por mês. Neste caso, é pouco provável que o diretor vá estabelecer intimidade com o funcionário em festas no apartamento deste. $\mathrm{O}$ estilo e os elementos estruturais das situações de festa tendem a diferir entre os dois, e de uma maneira que não atrai o superior.

A maneira mais promissora para um subordinado seduzir um superior é o velho e perenemente eficaz procedimento de adulação. É necessário elogiar o superior-alvo dentro da comunidade da organização. E, no que está a seu alcance junto a colegas e subordinados, o sedutor repudia, suprime ou reprime críticas e dúvidas destes sobre o que superior-alvo faz e diz, sobre sua pessoa e seu perfil profissional. Contudo, é preciso ir além: identificar e resolver dificuldades que o superior-alvo venha a ter, quer em sua atuação na organização, quer em sua vida pessoal. Servi-lo nos pequenos detalhes que as pessoas normalmente não notam ou em que, por discrição, não se imiscuem. Poupar-lhe das peque- 
nas frustrações que geram aborrecimentos (aquelas que são pequenas do ponto de vista do observador, mas que perturbam ou embaraçam quem as sente).

O superior seduzido passa a ver o subordinado sedutor como uma pessoa dedicada, prestativa, fiel; logo, como uma pessoa bondosa e, portanto, confiável. Como resultado, inverte-se a situação descrita anteriormente: a confiança do superior no subordinado torna-se imensa, de modo que aprova e chancela os atos deste sem a mínima relutância ou o menor traço de dúvida sobre a correção desses atos.

\subsection{FATORES DA PRÁTICA DE MALFEITOS}

O potencial praticante de malfeitos obtém de elementos estruturais da situação parte da capacidade de praticá-los (oportunidade) e parte da motivação (incentivo material). $\mathrm{O}$ interesse em elevar a própria renda de maneira ilícita pode vir não somente da ambição de desfrutar imediatamente um padrão de vida mais alto, como também de construir um patrimônio, obter segurança financeira e grande conforto no futuro. Quer dar mais segurança ao que já tem (Coleman, 1994, p. 195; Benson e Simpson, 2009, p. 71-72). Por isto, tem vontade quase ilimitada de ter mais.

Mas um interesse adicional, ou até mais importante, pode ser em benefícios menos diretos, tais como: obter status social; ostentar abundância material, luxo e gosto refinado; ostentar generosidade, desprendimento material e filantropia. Para outros, pelo menos em certo estágio da vida, a utilidade de bens materiais é secundária; praticam malfeitos porque é interessante ou excitante. São amantes do risco (Coleman, 1994, p. 194). Alguns cometem ilícitos porque para eles, diferentemente de seus colegas, é fácil. Sentir-se-iam trouxas se não o fizessem; fazendo-o, confirmam sua superioridade em inteligência e astúcia comparativamente às pessoas ordinárias. Entusiasmam-se com desafios ao ego (Benson e Simpson, 2009, p. 48, 51). Seguem um caminho, sem dúvida minoritário, em que inteligência, sagacidade e habilidades levam à ilicitude em vez de conduzirem à vida honesta.

Um importante elemento de oportunidade para malfeitos é número alto ou quantidade grande de itens, inclusive em grande variedade de categorias. No sentido abstrato da matemática, os itens são objetos contáveis. Em termos da prática do dia a dia, são contados pouquíssimas vezes e somente por seus responsáveis diretos. Quem não está diretamente envolvido dificil- 
mente seria capaz de estimar números e quantidades. Muito menos lhe ocorre fazê-los, tendo outras tarefas com que se preocupar.

Tenha-se em mente uma organização ou um empreendimento. Quase sempre a existência de um número grande ou uma quantidade grande de objetos valiosos faz parte da rotina, e a rotina cega ou adormece os sentidos; sobretudo quando os objetos se distribuem em diversas categorias. Assim, quase todos os membros da comunidade na organização envolvida deixam de notar a ausência de uma parcela; ou de notar que caixas e invólucros não estão preenchidos pelo conteúdo que deveriam. Pense-se em uma farmácia de hospital, um almoxarifado de laboratório ou de uma fábrica de medicamentos, abrigando milhares de cápsulas e porções de líquidos dos mais diversos tipos.

O número ou a quantidade de objetos valiosos pode ser grande, por exemplo, porque estes são componentes de: i) uma grande obra de construção (um túnel, uma barragem, uma refinaria, uma ferrovia, uma plataforma marítima); ii) reequipamento de uma organização (novos computadores em rede para todos os funcionários; armas e munições para uma força militar); iii) manutenção de uma organização (material de limpeza, estocagem preventiva de peças e de instrumentos que ficam defeituosas).

Ademais, esses objetos podem ser, na linguagem dos economistas, entes escriturais. Ou seja, consistem em registros de fluxos financeiros de compras, vendas, realização de depósitos em contas, retiradas de depósitos, desembolsos por gastos, recebimentos de receitas ou de financiamentos, de saldos credores e devedores em contas. Também se realizam aos milhares ou dezenas de milhares por mês em uma organização de tamanho médio.

Um elemento de incentivo à prática de malfeitos é um atrativo: o valor econômico alto dos objetos materiais ou dos entes escriturais (Schneier, 2006, p. 140). Casa-se com outro elemento de oportunidade, o aspecto de que estão na proximidade do potencial praticante. Estão, por assim dizer, ao alcance da mão ou à distância de alguns passos. Ademais, muitas vezes somente especialistas - fazendo perícia de documentos, de bens e de dívidas - pode constatar discrepâncias entre registro e realidade econômico-financeira (supervalorização ou sub-valorização de bens, de serviços, de ativos ou de passivos).

Mais um elemento de oportunidade é a complexidade de uma organização, onde se realizam inúmeras tarefas e de diferentes naturezas (Benson 
e Simpson, 2009, p. 43, 44). Há internamente uma divisão de trabalho, de modo que cada pessoa tem tarefas que são só suas. Em muitas delas, pouca gente observa, ou observa em detalhe o que um colega faz. Isto é especialmente importante onde os funcionários têm alta qualificação: cada advogado dá parecer sobre uma decisão, cada analista de investimentos se ocupa dos títulos financeiros de uma empresa, cada operador da mesa financeira faz operações que são só suas. Quando mais de uma pessoa se envolve, são em número pequeno, o que facilita conluio.

\subsection{O CAMPO DE OPORTUNIDADES}

É instrutivo examinar um panorama, ainda que parcial e incompleto, do campo de oportunidades. Assim se forma uma noção mais clara de quão vasto esse campo é. Um guia sobre oportunidades é a Lei de Sutton, como se pode chamar a explicação sintética e singela, dada por Willie Sutton, para seu costume de assaltar bancos em Nova Iorque nos anos 1950: "Lá é que há dinheiro" (Manchester, 1974, p. 730). A competência criminosa de Sutton marcou época e sua explicação continua deixando rastros nas ciências sociais e nas humanidades (por exemplo, David-Hillel, 1985, p. 140; Hammer e Stanton, 1995, p. 274; Gosler, 2005, p. 101; Schneier, 2006, p. 61; Pinker, 2013, p. 685).

Assim, reduza-se a dimensão da tarefa de expor o panorama, explorando-o na ótica da Lei de Sutton, que focaliza oportunidades financeiras: onde há muito dinheiro que pode levar sumiço ou ser desviado?

Há nos patrimônios de cada plano de saúde, fundo de pensão, fundo de aposentadoria, fundo de investimentos, reserva de seguros; em cada contrato vultoso de aquisição de equipamentos; em cada contrato de construção de instalações de empresas ou de obras públicas; em cada contrato de fornecimento de alimentação a hospitais e presídios; em cada contrato de serviços de vigilância, de limpeza e de publicidade; em cada grande empréstimo concedido por bancos públicos; em cada grande empréstimo tomado por órgão do Estado; em cada tesouraria de empresa ou órgão público; em cada falência, cada recuperação judicial ou extrajudicial de grande empresa.

Além de estoques e fluxos financeiros, há recursos materiais. A construção, a manutenção, o conserto ou a reforma de cada quilômetro de estrada, cada escola, posto de saúde, hospital, prédio de tribunal, estádio de espor- 
tes, praça, viaduto, túnel, monumento, jardim em logradouro público, poço, porto, terminal rodoviário ou de coletivos urbanos, pode ser superfaturada; pode ser realizada aquém do exigido nas especificações contratuais, tanto em dimensões físicas quanto em qualidade de componentes e de serviços. Sem que ninguém note, materiais, equipamentos, componentes, peças, móveis, podem desaparecer ou ser trocados por similares de qualidade inferior.

Outro elemento importante de capacidade para praticar malfeitos de colarinho branco é habilidades profissionais e pessoais do agente. Estas são necessárias porque as diferenciam dos malfeitos ordinários. Longe dos olhos dos colegas, um funcionário pode arrombar o almoxarifado ou um cofre da organização. Mas não conseguirá fazê-lo mais do que umas poucas vezes, pois este tipo de ação chama a atenção para seu resultado. Por esta razão, o praticante de malfeitos de colarinho branco não arromba, não realiza furto físico visível nem assalta; como meios de sua prática emprega suas habilidades profissionais e suas competências em cargos e funções.

Para consegui-lo, precisa ser reconhecido como bom profissional, dedicado, cooperativo, obediente; ter qualidades que não atraem sobre si suspeita, nem vigilância, nem oposição a suas atividades. Praticantes de malfeitos de colarinho branco são excepcionalmente hábeis em posar como profissionais capazes e como pessoas de bem. Naturalmente, também são necessárias habilidades de esconder e mascarar os atos ilícitos que cometem, tanto perante superiores e supervisores, como perante colegas.

Adquirir desafetos chama a atenção, atrai reações e foco sobre si. Para evitar isto, os agentes de ilicitudes têm certos talentos de relações pessoais. Assim, muitas vezes são pessoas gentis, amigáveis, boas de conversa, tendo facilidade de gerar credibilidade e confiança em relacionamentos (Benson e Simpson, 2009, p. 50). Aqueles que se fazem durões são, em contrapartida, respeitados e vistos como sérios e honestos. Ademais, são pessoas hábeis em cultivar a simpatia de quem tem poder ou liderança, prestando-lhes serviços, favores ou palavras de afago nos momentos certos.

Apesar das impressões de afetividade que dão, os praticantes de malfeitos de colarinho branco têm pouca ou nenhuma capacidade de sentir culpa ou remorso. Muitos são psicopatas. Não que assassinem ou batam em pessoas; apenas são indiferentes aos direitos que violem e aos sofrimentos que causem (Ekman, 1992, p. 67; Hare, 1993, c. 7). 


\section{Dificuldades de Prevenir e Debelar}

\section{I. CONDIÇÕES QUE FACILITAM A OCORRÊNCIA DE MALFEITOS}

Dentro de organizações, às vezes há membros que praticam delitos ou malfeitos de colarinho branco. Entre as principais dificuldades para preveni-los e debelá-los estão as condições que facilitam a ocorrência de malfeitos. Outras dificuldades importantes surgem de aspectos que levam a descoberta tardia de malfeitos ocorridos ou levam-nos a nunca serem descobertos; de aspectos que prejudicam a investigação e a definição de pessoas suspeitas a indicar em ação judicial; e de condições que prejudicam a ação judicial e a condenação.

Como se viu, facilitam a ocorrência de malfeitos os seguintes aspectos das atividades rotineiras das organizações: alguns itens de valor econômico existem em número alto ou em quantidade, inclusive em grande variedade de categorias. Esses itens podem ser materiais ou escriturais (lançamentos financeiros e registros documentais). Um aspecto importante é que não podem ser contados nem medidos com facilidade; ou são pouco observáveis; ou são verificáveis somente com considerável esforço, ou somente com conhecimento especializado.

\subsection{ASPECTOS QUE LEVAM A DESCOBERTA TARDIA}

Malfeitos de colarinho branco são descobertos muito tardiamente ou nunca o são. Assim ocorre porque eles não são visíveis, estando encobertos por uma cultura organizacional de não se olhar e não se falar (Bunt, 2010, p. 438). Dois elementos geram invisibilidade: aspectos dos atos e aspectos dos agentes.

Por sua vez, o primeiro elemento a gerar invisibilidade abrange dois aspectos cruciais dos atos:

i) o praticante simula realizar atos ordinários de sua função ou cargo, manipula documentos e registros, inclusive alterando-os, ocultando-os ou suprimindo-os. Tem condições propícias para dissimular e para acobertar com aparência de licitude o que fizer de irregular (Benson e Simpson, 2009, p. 80, 206). A ampla variedade de especialidades faz com que, na organização, cada pessoa tenha uns poucos colegas que possam entender o que a pri- 
meira faz. Mas, mesmo assim, como cada trabalho de um especialista tende a ser bastante específico, é comum também que um colega da mesma especialidade tenha somente uma noção geral e vaga da tarefa que o primeiro realiza.

Ilicitudes de colarinho branco são complexas do ponto de vista técnico, envolvendo o emprego sorrateiro e astucioso de conhecimento especializado . Por isto, são difíceis de detectar, investigar e provar (Jamieson, 1994, p. 65, 66; Benson e Cullen, 1998, p. 26). É simplória a noção de que em geral se sabe o que acontece na sala vizinha. Um funcionário de organização pública ou privada muitas vezes não consegue ver o que o colega ao lado está escrevendo ou está vendo na tela do computador. Não acompanha o colega quando este ou esta vai utilizar o telefone celular no banheiro.

É igualmente irrealista julgar-se que um superior em geral saiba em detalhe o que um subordinado faz ou como faz; e, muito menos provável, que um subordinado saiba o mesmo sobre seu superior.

ii) a vítima não nota o prejuízo que lhe ocorre, diferentemente das vítimas de assaltos, agressões e arrombamentos. Em parte, porque o praticante realiza atos sofisticados de especialidade técnica ou profissional. Muitas vezes a vítima não pode observar, nem saber, nem examinar, nem interpretar os itens, os documentos, as atividades técnicas envolvidas. Nem tem como confirmar a genuinidade ou a veracidade dos relatórios recebidos (Shapiro, 1984, p. 9-10; Benson e Simpson, 2009, p. 84). Ou não vale a pena fazê-lo rotineiramente. Ademais, toda confirmação depende de confiar em quem confirma, o que significa supor que este não está em conluio com aquele de quem se desconfia.

E, em parte, porque é somente anos depois que o proprietário de um fundo de investimentos ou o beneficiário de um fundo de pensão recebe as quantias a que tem direito. A empresa ou órgão público que paga por uma construção ou uma aquisição não percebe que o custo poderia ser menor. $\mathrm{O}$ número alto ou a quantidade grande de itens executados, contratados, comprados, vendidos, ou seja o que for, esconde a inexistência real ou a qualidade inferior de uma parcela deles.

O segundo elemento a gerar invisibilidade é o seguinte: o praticante não desperta suspeita do que pratica. Pelo contrário, é visto como respeitável e confiável. Conseguiu dissimular até o ponto de obter credibilidade (Mit- 
nick e Simon, 2005, p. 232-233). Logo, as supervisões e fiscalizações tendem a ser superficiais ou meramente rituais. Os próprios colegas, os subordinados ou os superiores do praticante ficariam indignados se este fosse submetido a uma supervisão rigorosa ou a uma fiscalização dura. Estas possivelmente seriam vistas como ofensas pessoais.

\subsection{ASPECTOS QUE PREJUDICAM A INVESTIGAÇÃO}

A investigação de malfeitos de colarinho branco é muito prejudicada por características bem próprias destes:

i) quando as vítimas descobrem ou suspeitam dos prejuízos que sofreram, já se passaram anos que os atos causadores foram praticados. A vítima está distante no tempo e no espaço dos atos ilícitos cometidos. E não sabe interpretá-los, porque não tem treinamento nas mesmas especialidades dos transgressores. Por isto, não é fácil à investigação encontrar bons informantes nem testemunhas úteis.

ii) a enormidade do número de itens e das quantidades envolvidas levam a que somente uma fração pequena seja supervisionada, aferida, verificada ou fiscalizada. É trabalhoso localizar a parcela pequena, mas crucial, de itens que indicam cometimento de malfeitos.

iii) é caro e demorado supervisionar, aferir, verificar ou fiscalizar, porque isto requer serviços de profissionais de alta especialização ou de alto nível de formação como aqueles que praticaram os atos; requer ler centenas ou milhares de documentos, examinar centenas ou milhares de lançamentos contábeis ou de notas fiscais, realizar demorados testes de laboratório etc.

iv) é difícil definir quais pessoas suspeitas indicar em ação judicial, porque muitas vezes elas se encobrem apoiando-se na informalidade. Quando o subordinado suspeito diz que cumpriu ordens verbais do superior, este alega que foi mal interpretado (Conklin, 1977, p. 118). Quando o superior suspeito diz que aprovou um ato porque ouviu explicações e justificativas verbais feitas pelo subordinado, é a vez deste alegar que foi mal interpretado.

v) colegas e subordinados de um suspeito evitam dar depoimentos e ajudar a coleta de elementos probatórios porque acreditam intensamente na sua inocência. Afinal, parece-lhes inacreditável que uma pessoa competente, 
dedicada, confiável, merecedora de credibilidade, gentil, pronta a ajudar, de sorriso charmoso e conversa cativante, tenha cometido os atos imputados pelos investigadores (Bunt, 2010, p. 442; Conklin, 1977, p. 118);

vi) em particular, quando foram pessoalmente ludibriados pelo suspeito, os colegas de trabalho resistem a dar-se conta de que uma pessoa tão próxima, por quem sentem afeto, tenha sido inescrupulosa e causado prejuízos friamente (Greenspan, 2009, p. 145). Esta é uma das situações em que as pessoas têm dificuldade de encarar e reconhecer a realidade, de desafiar suas crenças e de admitir erros (Ekman, 1992, p. 20). Quem nunca foi logrado seriamente por pessoa de sua longa e devotada amizade tende a crer que pessoas de sua confiança são garantia de toda hora.

vii) é comum que organizações tenham cultura interna marcada por regime administrativo de comando e controle (Braithwaite, 1984, p. 94, 288; Coleman, 1994, p. 209; McLean e Elkind, 2004, p. 92, 116-118, 204-205). Este regime, que gera uma cultura de sujeição, é bastante conhecido em empresas pelo eufemismo de 'ambiente interno competitivo'. Também se alude a 'cultura interna de arrogância' (Squires at al., 2003, p. 7-8, 13-14; McLean e Elkind, 2004, p. 241). O caso da Enron é um exemplo. Veja-se como um executivo explicou a relação entre Ken Lay, o presidente da empresa, e os membros da diretoria: "Whatever Ken wanted them to okay, they did" (McLean e Elkind, 2004, p. 97).

Sendo assim, colegas e subordinados de um suspeito evitam dar depoimentos porque temem represálias vindas do próprio suspeito - ou de sua 'turma da penumbra', que permanece na organização e tem meios administrativos de retaliar (Conklin, 1977, p. 118).

\subsection{CONDIÇÕES QUE PREJUdICAM A AÇÃo JUdiCIAL E A CON- DENAÇÃo}

Supondo-se que a evidência ('os elementos probatórios') contra o investigado é forte, cabe citar algumas das condições que prejudicam a ação judicial e a condenação:

i) disparidade econômica entre o acusado e a vítima, em detrimento desta. Muitas vezes, os acusados de malfeitos de colarinho branco são empresas ricas ou pessoas ricas, que podem contratar escritórios advocatícios de alto 
nível, enquanto que do lado da vítima pode estar um advogado modesto, um defensor público ou uma associação de defesa do consumidor. Mesmo quando o lado da vítima ou do acusador é representado por um órgão estatal de regulação, cabe notar que o Estado é rico, mas os órgãos de regulação podem ser mais pobres que os acusados. É comum que estes órgãos não possam bancar em número suficiente os serviços de especialistas necessários para a ação judicial.

ii) legisladores, juízes e até mesmo vítimas tratam com misericórdia os malfeitos de membros da classe social a que pertencem. Vêem-nas como pessoas respeitáveis, fundamentalmente honestas, as quais tiveram somente um momento de fraqueza moral (Conklin, 1977, p. 112-113). Pessoas de classe média e alta são mais tolerantes com as ilicitudes de pessoas que são agradáveis, provêm de boas famílias, têm a mesma formação, geram empregos, fazem doações de caridade, dão apoio a eventos culturais ou esportivos, ajudam as colocações profissionais dos colegas, ou conviveram na mesma faculdade, clube, time, igreja ou partido político. Aquelas pessoas veem como tortura o mero fato de alguém que é 'gente bem' estar detida. Em contraste, pessoas de baixo status social recebem dureza de coração e rigor no tratamento (Levi, 1987, p. 74).

\section{O Caso da Petrobras e O Cartel de Empresas}

A Operação Lava Jato, iniciada em 17 de março de 2014, com suas muitas ramificações e eventos, é assunto longo demais para os limites deste texto. Esta seção não tenta sequer um resumo. Vladimir Netto lançou um bom relato em livro (Netto, 2016). Rodrigo Chemim compara-a com a Operação Mãos Limpas e expõe com clareza aspectos jurídicos (Chemim, 2017). Ademais, as investigações continuam ocorrendo. Portanto, muitas das informações ainda estão sujeitas a acréscimos, reelaborações e retificações.

Contudo, no que concerne ao passo inicial da Lava Jato, o quadro panorâmico estabilizou-se cedo, em poucos meses. Desde o fim de 2014, a estória que se tem é, ao menos no global, a mesma. Esse passo é o que ocorreu diretamente com uma organização, a Petrobras. As ocorrências são instrutivas por formarem um caso exemplar em sua categoria de delitos de colarinho branco. Isto é, no que concerne a características gerais, o caso aproxima-se de uma descrição esquemática de muitos casos semelhantes que a literatura técnica internacional conhece. Por exemplo, contrato é uma palavra-chave. 
Contratos são um dos fatores mais frequentes de aplicar ou encontrar aplicação da Lei de Sutton dentro de organizações ou por organizações.

Somente o tamanho e o caráter estatal da Petrobras, além de seu prestígio, formam os aspectos em que o caso está entre os menos comuns. Naturalmente, as duas primeiras características foram determinantes dos imensos valores de contratos, de propinas e de fluxos financeiros suspeitos, bem como do grande número de empresas privadas e de nomes de 'gente bem' envolvidos (executivos, empresários, políticos).

Empresas de construção civil, estaleiros e fornecedoras de equipamentos tinham oportunidades de obter contratos com a Petrobras; combinavam entre si quais delas participariam de licitação ou de convite e qual venceria. Ou seja, formavam um cartel para elevar o valor econômico dos contratos, que correspondia a receita conjunta da combinação de empresas. Um ou outro diretor da Petrobras, aliado e beneficiário do cartel, viabilizava internamente a concordância da diretoria com a necessidade das licitações. Ademais, facilitava os termos das licitações e dos contratos, fornecia informações vitais ao cartel, bem como viabilizava a posterior aprovação de contratos superfaturados e de sucessivos aditivos contratuais.

Importantes obras e equipamentos eram para refinarias, gasodutos e exploração marítima. Entre elas, construção e aluguel de navios-sondas e de plataformas flutuantes marítimas. Em sequência à descoberta das ocorrências na Petrobras, várias dezenas de pessoas aceitaram prestar colaboração premiada à justiça. Constatou-se como vinculada ao cartel a atuação de ex-diretores de três diretorias da Petrobras: da Diretoria de Abastecimento (Paulo Roberto Costa), da Diretoria Corporativa e de Serviços (Renato Duque), bem como da Diretoria Internacional (Nestor Cerveró; Jorge Zelada). Dentre chefes de alto nível, destacam-se algo como três ou quatro ex-gerentes - sendo Pedro Barusco o mais conhecido, tanto por ter sido diretor de outra empresa envolvida nas ações ilícitas, a Sete Brasil, como por sua competência profissional. As cinco pessoas citadas tornaram-se réus e foram condenadas pela justiça em primeira instância.

Pagamentos de propina eram feitos pessoalmente em espécie ou em contas no exterior dos beneficiados, bem como a intermediários destes - ora pessoas físicas (às vezes familiares de um diretor), ora empresas de fachada (várias no exterior, conhecidas como empresas offshore). Uma empresa pagadora de propina poderia usar uma subsidiária sua ou uma construtora sub- 
contratada para ser intermediária, mas era frequente que lançasse mão de empresas prestadoras de serviços de consultoria, de assessoria, de qualificação e capacitação profissional e de outros tipos. Os serviços não eram prestados ou tinham valor econômico muito abaixo das quantias que as alegadas prestadoras recebiam. Também se empregavam empresas que se apresentavam como sendo de comércio exterior. Parte substancial das propinas era entregue na forma de doações a partidos políticos e às finanças de campanhas políticas individuais de candidatos.

Ainda em 2014 levantou-se a informação de que 16 empresas construtoras comporiam o cartel. Entre elas, conforme citado em Comissão Parlamentar de Inquérito, as seguintes: Andrade Gutierrez, Camargo Correa, Engevix, Galvão Engenharia, Iesa, Mendes Júnior, MPE, OAS, Odebrecht, Promon, Queiroz Galvão, Setal, Skanska e UTC (Jornal da Câmara, 2014, 2015a, 2015b, 2015c). Naturalmente, o esquema de dilapidação da Petrobras incluia outras empresas; algumas estrangeiras, tais como a coreana Samsung e a holandesa SBM Offshore. Também abrangia dezenas de empresas pequenas que serviam ou poderiam servir para ocultar a origem ilícita de fluxos financeiros. Por exemplo, Paulo Roberto Costa e familiares tinham 13 empresas de consultoria e assessoria (Netto, 2016, p. 60)

Conforme a sociedade brasileira tomou conhecimento em 14 de novembro de 2014, o vulto, a extensão e o significado do caso Petrobras iam muito além do que se vira em trabalhos anteriores da Polícia Federal e do Ministério Público Federal. Nesse dia foram detidos dirigentes de sete das maiores empreiteiras brasileiras, além de buscas e apreensões em oito delas (Netto, 2016, p. 90, 93). Entre os dirigentes estavam donos, presidentes, vice-presidentes, diretores e altos executivos. Genuinamente, e não como chavão de jornais, ocorrera um fato surpreendente e inédito na história brasileira.

Cabe comentar alguns aspectos do caso:

i) Pelo que se divulgou até agora, aparentemente o esquema lesivo não corrompeu ocupantes do posto de presidente, dos outros quatro postos de diretor (diretorias financeira, de gás e energia, de exploração e produção, bem como de engenharia, tecnologia e materiais), de oito membros do conselho de administração nem de cinco membros do conselho fiscal na Petrobras. Ou, pelo menos, as suspeitas sobre estes postos foram tão menores que não mereceram divulgação. 
ii) E de fato, a julgar por casos de grandes organizações na experiência internacional, esquemas lesivos tendem a conseguir somente contaminação parcial da estrutura. Isto quer dizer que, em geral, a organização não vira 'um antro de corruptos', 'um covil de ladrôes'. A maior parte da estrutura e do pessoal permanece limpa, intacta, além de ter uma parcela recuperável.

Não que o risco corrido por uma grande organização não seja imenso. Basta um diretor, ou às vezes um só gerente de segundo ou terceiro escalão, para quebrar definitivamente uma empresa. Aconteceu, por exemplo, com o Barings Bank em 1995, o mais antigo banco mercantil da Grã Bretanha, que tinha a família real entre os clientes. Note-se também que a parte limpa é sempre um recurso à disposição de procedimentos que se possam desenhar para prevenir delitos e malfeitos de colarinho branco dentro ou por organizações.

iii) Contudo, como se viu na seção 4 deste texto, os praticantes de malfeitos precisam conseguir domínio sobre documentos e sobre pessoas. Nesse tipo de caso, os diretores delinquentes engabelam os diretores limpos e o conselho de administração, bem como ganham certa ascendência sobre estes. Os meios de engabelar são documentos, pareceres técnicos, tabelas de dados, previsões e prospecções - aqui ou acolá, adulterados, distorcidos ou enviesados. Naturalmente, também a omissão proposital (engavetamento, perda, destruição) de documentos e de informações que venham contra os objetivos dos diretores delinquentes.

Ganha-se ascendência por meio de pressão social. Os dirigentes delinquentes constroem dentro da organização, e sobretudo no grupo dos outros dirigentes, a imagem de que são visionários conhecedores das excelentes perspectivas futuras da organização, são inovativos, são empreendedores, extravasam dinamismo. Têm norte e rumo, têm projetos. A qualquer objeção de cautela, respondem que quem não arrisca não petisca. Que os outros dirigentes têm fixação burocrática, são lentos, alimentam inércia na organização, são medrosos, atrasam o desenvolvimento da organização. Assim, os dirigentes tidos por 'acomodados' e 'de visão tacanha' sentem-se na defensiva, tremem a voz antes de criticar os planos ousados, 'inovadores' e 'brilhantes' dos dirigentes 'dinâmicos'.

iv) Como se viu na seção 4 deste texto, as 'turmas das penumbras' ('seções de operações veladas') só prosperam sob a chefia de diretores se estes conseguirem convencer, seduzir ou pressionar funcionários subordinados. 
Do ponto de vista de tragédias pessoais, esta é a mais entristecedora do caso Petrobras. Já em julho de 2015, a Controladoria Geral da União investigava 58 ex-dirigentes e empregados da Petrobras, ao lado de ter em andamento 19 processos administrativos disciplinares, bem como 30 processos contra empresas (Jornal da Câmara, 2015d).

A mídia informa pouco ou nada desse tópico. Porém, é razoável conjecturar que hoje há centenas de funcionários da Petrobras, daqueles de nomes desconhecidos e sem eventos de interesse midiático nas suas carreiras profissionais, sendo investigados administrativa e judicialmente, respondendo a sindicâncias e a processos. Foram as presas intraorganizacionais. Pagam agora um enorme preço; para alguns, da falta de coragem diante do bote do predador em épocas do passado; para outros, da solidão e do isolamento burocrático intraorganizacional: precisavam de apoio para resistir ao bote, mas não tinham a quem recorrer. Não viam, não sabiam em quem confiar dentro da organização. Todos, para não beber o cálice amargo na época, optaram por obedecer ao 'cale-se'.

v) Os dirigentes, os chefes inferiores e os funcionários que foram ou estão sendo investigados ou acusados desde 2014 formam um grupo selecionado por critérios que, sob certo ângulo, são muito exigentes. É o grupo, diga-se assim, somente dos muito 'malvados'. Entrou nele quem apresentou indícios de ter cometido faltas de natureza penal (caindo na mira da Polícia Federal e do Ministério Público Federal) ou ter violado normas internas da organização (caindo na mira de processos administrativos).

Contudo, boa parte de quem não entrou nesse grupo não é inteiramente limpa ou intocada pelo mal. Nesta parte estão os que nunca foram atacados pelos predadores; mas perceberam, olharam melhor e descobriram o que acontecia. E como ninguém poderia mostrar que eles sabiam, calaramse e recolheram-se em seus cantos. Cometeram falha moral, mas dessas que nenhuma comissão de ética seria capaz de indicar. Falha personalíssima. A seriedade da falha, obviamente, é inversamente proporcional à intensidade de coragem que precisariam ter e à magnitude das retaliações que sofreriam, caso optassem por revelar o que descobriram.

vi) Mais importante é a possibilidade de que alguns, de boa fé, podem ter causado danos à organização, alterando práticas e modificado procedimentos, sem que estas alterações e modificações sejam ilegais ou contra normas. Em princípio, são alternativas aceitáveis técnica ou profissionalmente. No entanto, elas 
podem ter sido feitas sob pressão dos dirigentes 'dinâmicos', não por livre iniciativa de quem fez. Foram feitas como forma de conciliação de relações com gente tão impositiva. Para não parecer que se lhes negava tudo, que se fazia oposição a tudo. Foram feitas diante da alegação de que não se coopera, de que não se tem espírito de comunidade. Como se sabe, esta é uma das formas mais comuns de chantagem sem ameaças em relações interpessoais - nas amizades ou no trabalho. Existe desde quando se é criança, e é conhecida por 'chamar nomes' ('você é feio').

Obviamente, os dirigentes malfeitores queriam essas alterações, que provavelmente foram descritas como 'aperfeiçoamentos', 'atualizações', 'modernizações', 'dinamizações', 'desburocratizações' da organização. A possibilidade de danos é que elas podem ter inserido, por assim dizer, buracos na muralha; podem ter aberto portas nas paredes de trás. Dito de outro modo, podem ter introduzido fraquezas institucionais que eles pretendiam utilizar em atuações ilícitas futuras e que facilitariam ações de 'turmas das penumbras'. Fraquezas que, se não forem identificadas, permanecem a aguardar quem, no futuro, venha a perceber a oportunidade de novos malfeitos.

\section{Comentários Finais}

Exposto neste texto, o 'modelo de seção de operações veladas' limitase ao que pode ocorrer dentro de uma organização. No entanto, dá uma ideia inicial das dimensões das dificuldades nas tarefas de prevenir, detectar, investigar e debelar delitos e malfeitos de colarinho branco. E permite vislumbrar o que pode ter acontecido dentro da Petrobras, no seu dia a dia, enquanto se praticavam os delitos e malfeitos revelados pela Operação Lava Jato.

Com a finalidade de aperfeiçoar e fortalecer essas tarefas, é necessário conhecer mais. Trabalhos de pesquisa que exponham a variedade de espécies de malfeitos de colarinho branco, bem como seu cometimento nas relações entre organizações do mais diversos tipos, servirão para aprofundar as reflexões sobre o problema.

VALDir Melo

Doutor em economia pela Escola de Pós-Graduação em EcoNomia da Fundação Getulio Vargas. É pesquisador (Técnico de Planejamento e Pescuisa) no Instituto de Pescuisa EconôMicA APLicAda - IPEA - Brasil.

E-MAIL:VALDIR.MELO@IPEA.GOV.BR 


\title{
A Model of White Collar Wrongdoings Inside Organizations
}

\begin{abstract}
A simple model as the one in the text explains the occurrence of white collar crimes and wrongdoings inside an organization. It helps one to identify obstacles to preventing and restraining those unlawful actions. Such obstacles result from: conditions that make it easy to commit violations of law and of morality; characteristics that hamper investigation and accurate circumscribing, among the suspects, of those that should be named in judicial proceedings; conditions that hinder judicial proceedings and obtaining conviction. Moreover, the model inspires some considerations on the case of Petrobras and the related business cartel.
\end{abstract}

KeYwORDs: White collar crime. Crime inside organizations. Wrongdoings. Obstacles to preventing and restraining. Petrobras.

\section{Un Modelo de Delitos de Collar Blanco DENTRO DE ORGANIZACIONES}

\section{RESUMEN}

Un modelo simple, como este expuesto en este texto, explica la comisión de delitos y malentendidos de cuello blanco dentro de una organización. Ayuda a identificar las dificultades de prevenir y de golpear tales delitos intraorganizacionales. Se derivan de: condiciones que facilitan la ocurrencia de delitos; aspectos que llevan al descubrimiento tardío de delitos ocurridos o llevan a nunca ser descubiertos; aspectos que perjudican la investigación y la definición de personas sospechosas a indicar en acción judicial; condiciones que perjudican la acción judicial y la condena. Además, el modelo inspira algunas consideraciones sobre el caso de Petrobras y el cártel de empresas.

Palabras Clave: Delitos de cuello blanco. Crimen en organizaciones. Malentendidos. Dificultades para prevenir y de golpear. Petrobras.

\section{REFERÊNCIAS}

ARVEDLUND, Erin. Too good to be true: the rise and fall of Bernie Madoff. New York: Portfolio, 2009.

BENSON, Michael; CULLEN, Francis. Combating corporate crime. Boston: Northeastern University Press, 1998. ; SIMPSON, Sally. White-collar crime: an opportunity 
perspective. New York: Routledge, 2009.

BLUMBERG, Paul. The predatory society: deception in the American marketplace. New York: Oxford University Press, 1989.

BOGDANICH, Walt. The great white lie: dishonesty, waste, and incompetence in the medical community. New York: Touchstone, 1991.

BRAITHWAITE, John. Corporate crime in the pharmaceutical industry. London: Routledge \& Kegan Paul, 1984.

BRYCE, Robert. Pipe dreams: greed, ego, and the death of Enron. New York: Public Affairs, 2002.

BUNT, Henk van de. Walls of secrecy and silence: the Madoff case and cartels in the construction industry. Criminology \& Public Policy, v. 9, n. 3, p. 435-453, 2010.

CHEMIM, Rodrigo. Mãos Limpas e Lava Jato: a corrupção se olha no espelho. Porto Akegre: CDG, 2017.

COLEMAN, James W. The crime elite: the sociology of white-collar crime. 3rd. ed. New York: St Martin's Press, 1994.

CONKLIN, John. "Illegal but not criminal": business crime in America. Englewood Cliffs (NJ): Prentice-Hall, 1977.

DAVID-HILLEL, Ruben. The metaphysics of the social world. London: Routledge \& Kegan Paul, 1985

EKMAN, Paul. Telling lies: clues to deceit in the marketplace, politics, and marriage. New York: W. W. Norton, 1992.

FOX, Loren. Enron: the rise and fall. Hoboken (NJ): John Wiley \& Sons, 2003.

FUSARO, Peter; MILLER, Ross. What went wrong at Enron. Hoboken (NJ): John Wiley \& Sons, 2002.

GIANNETTI, Eduardo. Auto-engano. São Paulo: Companhia das Letras, 1997.

GOSLER, James. The digital dimension. In: SIMS, Jennifer; GERBER, Burton (Eds.). Transforming U. S. intelligence. Washington (DC): Georgetown University Press, 2005, p. 96-114. 
GREENSPAN, Stephen. Annals of gullibility: why we get duped and how to avoid it. Westport (CT): Praeger, 2009.

HAMMER, Michael; STANTON, Steven. The reengineering revolution: a handbook. New York: Harper Business, 1995.

HARE, Robert. White-collar psychopaths. In: HARE, Robert. Without conscience: the disturbing world of the psychopaths among us. New York: Guilford Press, 1993. c. 7, p. 102-123.

JAMIESON, Katherine. The organization of corporate crime. Thousand Oaks (CA): Sage Publications, 1994.

JORNAL DA CÂMARA. Oposição quer reunião de emergência da CPMI. Jornal da Câmara, 10 out. 2014, p. 2.

. CPI ouve depoimento de Barusco, delator da Lava Jato. Jornal da Câmara, 10 de março de 2015a, p. 3.

. Barusco: corrupção na Petrobras foi institucionalizada a partir de 2004. Jornal da Câmara, 11 de março de 2015b, p. 8.

. CPI da Petrobras ouve mais dois executivos. Jornal da Câmara, 2 de junho de 2015c, p. 7.

. CGU processa 30 empresas por danos à Petrobras. Jornal da Câmara, 17 de julho de 2015d, p. 7 .

LEBOR, Adam; BOYES, Roger. Seduced by Hitler: the choices of a nation and the ethics of survival. Naperville (Ill): Sourcebooks, 2000.

LEVI, Michael. Regulating fraud: white-collar crime and the criminal process. London: Tavistock Publications, 1987.

MANCHESTER, William. The glory and the dream: a narrative history of America 1932-1972. v. 1. Boston: Little, Brown and Company, 1974.

McCLEAN, Bethany; ELKIND, Peter. The smartest guys in the room. New York: Portfolio, 2003.

MITNICK, Kevin; SIMON, William. The art of intrusion. Indianapolis (IN): Wiley, 2005.

NETTO, Vladimir. Lava Jato: o juiz Sergio Moro e os bastidores da operação que abalou o Brasil. Rio de Janeiro: Primeira Pessoa, 2016. 
OPPENHEIMER, Jerry. Madoff with the money. Hoboken (NJ): John Wiley \& Sons, 2009.

PINKER, Steven. Os anjos bons da nossa natureza. São Paulo: Companhia das Letras, 2013.

SCHNEIER, Bruce. Beyond fear: thinking sensibly about security in an uncertain world. New York: Springer, 2006.

SHAPIRO, Susan. Wayward capitalists: target of the Securities and Exchange Commission. New Haven: Yale University Press, 1984.

SPARROW, Malcolm. License to steal: Why fraud plagues America's health care system. Boulder: Westview Press, 1996.

SQUIRES, Susan; SMITH, Cynthia; McDOUGALL, Lorna; YEACK, William. Inside Arthur Andersen: shifting values, unexpected consequences. Upper Saddle River (NJ): FT Prentice Hall, 2003.

STONE, Christopher. Where the law ends: the social control of corporate behavior. New York: Harper Torchbooks, 1975.

STROBER, Deborah; STROBER, Gerald. Catastrophe: the story of Bernard L. Madoff, the man who swindled the world. Beverly Hills (CA): Phoenix Books, 2009.

WRONG, Dennis. Power: its forms, bases and uses. Chicago: University of Chicago Press, 1988.

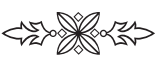

